\title{
PROGRAM PENERAPAN PELAPORAN INDIKATOR MUTU DAN KESELAMATAN PASIEN DI RUMAH SAKIT DAERAH TIPE C PROVINSI SULAWESI SELATAN: SEBUAH PENGABDIAN MASYARAKAT
}

\section{PROGRAM FOR IMPLEMENTATION OF REPORT OF QUALITY INDICATORS AND PATIENT SAFETY IN TYPE-C CITY HOSPITAL, SOUTH SULAWESI PROVINCE: A COMMUNITY SERVICE}

\author{
Razak Abdullah $^{\# 1}$, Syahrul Syahrul*2, Abdul Majid ${ }^{\# 3}$

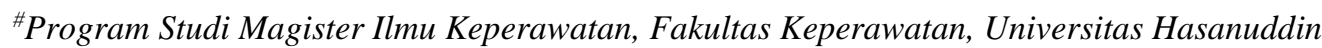 \\ Jalan Syech Yusuf Kota Kendari \\ lemail.razak.abdullah.s@gmail.com \\ ${ }^{3}$ email.abdul.majidunhas@gmail.com \\ *Bagian Keperawatan Komunitas, Keluarga, dan Gerontik, Fakultas Keperawatan, Universitas Hasanuddin \\ Nusa Tamalanrea Indah Makassar \\ ${ }^{2}$ email.syahrulsaideunhas.ac.id
}

\begin{abstract}
Abstrak
Pelaporan indikator mutu dan keselamatan pasien merupakan hal penting dalam Peningkatan Mutu dan Keselamatan Pasien(PMKP) di Rumah Sakit (RS) sebab HAL TERSEBUT dapat digunakan oleh komite PMKP sebagai bahan koreksi untuk organisasi DALAM RANGKA memperbaiki sitem pelayanan. Program pengabdian pada masyarakat ini bertujuan untuk membantu menemukan masalah yang ada di RS dan mnyelesaikan masalah dengan mengaplikasikan metode problem solving dalam manajemen keperawatan, yaitu identifikasi masalah, menyusun rencana intervensi dan implementasi sesuai masalah yang ditemukan, dengan pendekatan partisipasi aktif dari kelompok yang dibina dalam hal ini adalah perawat di rumah sakit daerah tipe $\mathrm{C}$, baik perawat manajer maupun perawat pelaksana, sehingga diharapkan dapat memberikan kontribusi pada upaya PMKP. Hasil yang diperoleh dari pengabdian ini adalah teridentifikasinya masalah dalam pelaporan indikator mutu dan keselamatan pasien, yaitu belum adanya profil dan indikator mutu, belum maksimalnya pelaksanaan sosialisasi profil dan indikator mutu dan belum optimalnya pendampingan pengisian format indikator mutu. Untuk mengatasi masalah yang dihadapi, perlu dilakukan penyusunan indikator mutu, sosialisasi profil dan indikator mutu, serta melakukan pendampingan dalam pengisian format indikator mutu. Kesimpulan: profil dan indikator mutu sebagai pedoman pelaporan indikator mutu, sosialisasi memberikan pengaruh dalam peningkatan pengetahuan perawat khususnya dalam hal pelaporan indikator mutu, dan pendampingan dapat meningkatkan motivasi dan tingkat pengetahuan perawat dalam pelaporan indikator mutu.
\end{abstract}

Keywords—pelaporan indikator mutu, keselamatan pasien, pelayanan kesehatan

Abstract

Reporting quality indicators and patient safety is important in Improving Patient Quality and Safety (PMKP) in Hospitals (RS), because it can be used as a correction material for organizations to improve service systems. This community service program aimed to help in finding problems in the hospital and solve problems by applying problem solving methods in nursing management, namely problem identification, planning interventions and implementation according to the problems found, with an active participation approach from the group that is fostered in terms of these are nurses in type $\mathrm{C}$ regional hospitals, both manager nurses and implementing nurses, so it is hoped that they can contribute to the efforts of the PMKP. The results obtained from this community service are the identification of problems in reporting quality and patient safety indicators, namely the absence of profiles and quality indicators, not yet maximizing the implementation of profile and quality indicators and not yet optimally assisting in filling the form of indicators of quality. . To overcome the problems, it is necessary to prepare quality indicators, socialize profiles and quality indicators, and provide assistance in filling out the quality indicator format. Conclusion: profile and quality indicators as guidelines for reporting quality indicators, socialization has an influence in increasing nurses 'knowledge, especially in terms of reporting quality indicators, and mentoring can increase nurses' motivation and knowledge in reporting quality indicators.

Keywords — quality indicator reporting, patient safety, health services 


\section{PENDAHULUAN}

Rumah sakit merupakan bagian penting dari sistem kesehatan. Rumah sakit menyediakan pelayanan kuratif komplek, pelayanan gawat darurat, pusat alih pengetahuan dan teknologi dan berfungsi sebagai pusat rujukan. Rumah sakit harus senantiasa meningkatkan mutu pelayanan sesuai dengan harapan pelanggan untuk meningkatkan kepuasan pemakai jasa. Dalam UndangUndang Nomor 44 Tahun 2009 Tentang Rumah Sakit, Pasal 29 huruf b menyebutkan bahwa rumah sakit wajib memberikan pelayanan kesehatan yang aman, bermutu, anti diskriminasi dan efektif dengan mengutamakan kepentingan pasien sesuai dengan standar pelayanan rumah sakit, kemudian pada Pasal 40 ayat (1) disebutkan bahwa dalam upaya peningkatan mutu pelayanan rumah sakit wajib dilakukan akreditasi secara berkala minimal tiga tahun sekali.

Sesuai dengan standar akreditasi rumah sakit, sebagai bagian peningkatan kinerja, rumah sakit secara teratur melakukan penilaian terhadap Indikator mutu area klinik, indicator mutu area manajemen dan indicator mutu sasaran keselamatan pasien yaitu indicator mutu yang mngukur kepatuhan staf dalam penerapan sasaran keselamatan pasien dan budaya keselamatan (KARS, 2017).

Laporan Institute of Medicine di Amerika Serikat yang berjudul „To err is human: building a safer health system" menyatakan bahwa 58\% dari 98000 kesalahan yang mengakibatkan kematian ternyata dapat dicegah.[1] Laporan tersebut juga mengungkapkan penelitian di rumah sakit Utah dan Corolado yaitu ditemukan Kejadian Tidak Diharapkan (KTD/Adverse Event) sebesar 2,9\% dengan 6,6\% diantaranya meninggal sedangkan di New York sebesar 3,7\% dengan angkan kematian 13,6\%. Angka kematian akibat KTD pada pasien rawat inap di Amerika yang berjumlah 33,6 juta pada tahun 1997 berdasarkan penelitian di Utah, Corolado dan New York adalah berkisar 44.000 sampai 98.000. Publikasi WHO tahun 2004 mengenai angka penelitian rumah sakit di Amerika, Inggris, Denmark, dan Australia menemukan KTD sebesar $3,2-16,6 \%$. Berbagai negara selanjutnya segera mengembangkan sistem peningkatan mutu dan keselamatan pasien mempertimbangkan data tersebut (Mc Fadden et al, 2009).

Pelaporan indikator mutu dan keselamatan pasien menjadi hal penting dalam perbaikan mutu pelayanan, sebab data tersebut dapat dijadikan bahan evaluasi bagi organisasi untuk memperbaiki sistem pelayanan yang ada di RS.

Pengabdian masyarakat sebelumnya juga pernah dilakukan oleh Harsul, Syahrul, \& Majid (2018), namun hanya berfokus pada penerapan budaya pelaporan insiden keselamatan pasien. Program pengabdian ini dilakukan di salah satu RS Daerah Provinsi Sulawesi Selatan. RS ini merupakan salah satu fasilitas pelayanan kesehatan dengan tipe C milik pemerintah daerah. RS ini menyediakan berbagai jenis pelayanan kesehatan baik rawat jalan maupun rawat inap dengan kapasitas tempat tidur sebanyak 106 buah.

\section{TARGET DAN LUARAN}

Target luaran yang diharapkan dalam kegiatan penerapan pelaporan mutu ini adalah: disusunya profil dan indicator mutu area klinik selanjutnya profil dan indicator mutu ini disosialisasikan ke rumah sakit agar dapat meningkatkan mutu dan menjaga keselamatan pasien.

\section{METODE PELAKSANAAN}

Program pengabdian masyarakat dilakukan di sebuah Rumah Sakit Umum Daerah Tipe C di Provinsi Sulawesi Selatan pada periode September November 2018. Tahapan pengabdian masyarakat adalah sebagai berikut:

\section{Tahap Penentuan Masalah}

Tahap penentuan masalah diawali dengan melakukan pengkajian atau pengumpulan data yang dilaksanakan pada tanggal 10 September26 September 2018 di seluruh ruang perawatan dan ruang kritis (UGD, ICU dan perinatologi). Metode yang digunakan dalam pengumpulan data yaitu metode kualitatif dan kuantitatif. Pengambilan data kualitatif yang pertama dilakukan dengan wawancara semi terstruktur selama 30-60 menit kepada Kepala Seksi Pelayanan Medik dan Keperawatan dan yang kedua dengan Focus Group Discussion (FGD) kepada seluruh kepala ruangan perawatan dan ruang kritis yang terdiri dari 8 kepala ruangan dan 1 ketua tim. Sedangkan pengumpulan data kuantitatif dengan penyebaran kuesioner kepada 57 perawat pelaksana.

2. Tahap Identifikasi dan Prioritas Masalah Tahap identifikasi dan prioritas masalah dilakukan pada tanggal 27 September- 3 Oktober 2018. Identifikasi masalah dilakukan dengan Focus Group Discussion (FGD). Hasil identifikasi masalah kemudian dilakukan penentuan prioritas masalah dengan melihat 3 aspek utama yaitu kegawatan (Urgency), tingkat mendesak (Seriousness) dan tingkat pertumbuhan (Growth) yang disingkat dengan "USG". Penilaian dilakukan dengan menggunakan skala likert 1-5. 1= sangat kecil/rendah pengaruhnya, $2=$ kecil pengaruhnya, 3 =sedang/cukup berpengaruh, 4=besar/tinggi 
pengaruhnya, 5=sangat besar pengaruhnya. Penilaian USG dilakukan dengan penyebaran kuesioner kepada 12 perawat manager yang mewakili ruang perawatan.

3. Tahap Analisis Masalah dan Rencana Kegiatan. Analisis masalah dilakukan dengan menggunakan analisis fish bone dan analisis SWOT. Hasil analisis SWOT dilakukan penilaian dengan menggunakan skala likert 1-4. Pembobotan dengan nilai $1=$ tidak penting $(\mathrm{TP})$, 2=sedang $(\mathrm{S}), 3=$ penting $(\mathrm{P}), 4=$ sangat penting (SP) dan pemeringkatan dengan nilai $1=$ kecil (K), 2=sedang (S), 3=besar (B), 4=sangat besar (SB). Penilaian SWOT dilakukan dengan penyebaran kuesioner kepada 11 perawat manager dengan hasil pengembangan diagram layang kuadran I dimana Rumah Sakit mempunyai peluang dan kekuatan sehingga dapat memanfaatkan peluang yang ada secara maksimal. Hasil analisis kemudian dilakukan Focus Group Discussion (FGD) pada tanggal 5 Oktober 2018 kepada 15 peserta yang terdiri dari jajaran manager yaitu Direktur Rumah Sakit hingga Kepala Ruangan untuk melakukan diskusi terkait kegiatan-kegiatan yang akan dilakukan untuk mengatasi masalah yang telah ditemukan. Adapun kegiatan yang disepakati akan dilakukan untuk mengatasi masalah yang telah ditemukan adalah:

a. Penyusunan profil dan indikator mutu area klinik

b. Sosialisasi profil dan indikator mutu area klinik

Kegiatan yang telah disepakati kemudian mengalami perubahan kegiatan pada saat implementasi yang dilaksanakan dengan melakukan 3 kegiatan yaitu:

a. Penyusunan profil dan indikator mutu area klinik

b. Sosialisasi profil dan indikator mutu area klinik

c. Pendampingan pengisian format indikator mutu area klinik

Kegiatan tersebut di atas dilakukan dengan melalui tahap persiapan, tahap pelaksanaan dan tahap evaluasi.

Tabel 1 menjabarkan tentang jenis kegiatan yang telah dilakukan, tahap persiapan setiap kegiatan, waktu pelaksanaan setiap kegiatan sasaran kegiatan dan metode yang digunakan dalam melaksanakan kegiatan.
.Tabel 1. Pelaksanaan Implementasi Kegiatan

\begin{tabular}{|c|c|c|c|}
\hline Kegiatan & $\begin{array}{c}\text { Waktu } \\
\text { Pelaksanaan }\end{array}$ & Sasaran & Metode \\
\hline $\begin{array}{l}\text { Penyusunan } \\
\text { profil dan } \\
\text { indikator mutu } \\
\text { area klinik } \\
\end{array}$ & $\begin{array}{c}9 \text { Oktober - } \\
18 \text { Oktober } \\
2018\end{array}$ & Komite PMKP & Diskusi \\
\hline $\begin{array}{c}\text { Sosialisasi } \\
\text { profil dan } \\
\text { indikator mutu } \\
\text { area klinik }\end{array}$ & $\begin{array}{c}23 \text { Oktober - } \\
31 \text { Oktober } \\
2018\end{array}$ & $\begin{array}{c}\text { Kepala } \\
\text { rungan, ketua } \\
\text { tim, Person in } \\
\text { Charge(PIC) } \\
\text { dan perawat } \\
\text { pelaksana. }\end{array}$ & $\begin{array}{c}\text { Ceramah } \\
\text { dan } \\
\text { diskusi }\end{array}$ \\
\hline $\begin{array}{c}\text { Pendampingan } \\
\text { pengisian } \\
\text { format indi }\end{array}$ & $\begin{array}{c}23 \text { Oktober }- \\
16 \text { November } \\
2018\end{array}$ & $\begin{array}{c}\text { Ketua Tim, } \\
\text { PIC dan } \\
\text { perawat } \\
\text { pelaksana }\end{array}$ & $\begin{array}{c}\text { Ceramah } \\
\text { dan } \\
\text { diskusi }\end{array}$ \\
\hline
\end{tabular}

\section{HASIL DAN PEMBAHASAN}

Kegiatan penerapan pelaporan indikator mutu dan keselamatan pasien di Rumah Sakit memiliki hasil dengan rincian sebagai berikut:

1. Penyusunan profil dan indikator mutu area klinik

Pada tanggal 18 oktober telah dilaksanakan penyusunan Profil dan indicator mutu klinik setelah melakukan kajian literatur dari buku SNARS 2018 serta hasil studi banding Tim PMKP tanggal 21 Maret 2018 di salah satu Rumah Sakit Umum Daerah Provinsi Sulawesi Selatan yang sudah akreditasi paripurna. Gambar 1 merupakan profil dan indikator mutu yang telah disusun.

Latar belakang dari pelaksanaann kegiatan ini adalah data dari komite PMKP bahwa belum adanya indicator mutu area klinik RS, namun menurut aturan (KARS,2017) menyatakan bahwa Rumah sakit bersedia bergabung dalam sistem penilaian perkembangan mutu dengan memberikan hasil pengukuran indikator mutu. Apabila rumah sakit tidak bersedia bergabung dalam sistem penilaian perkembangan mutu dengan memberikan hasil pengukuran indikator mutu hal ini dapat berakibat pada hasil akreditasi.

2. Sosialisasi profil dan indikator mutu

Sosialisasi profil dan indicator mutu area klinik dilakukan selama tujuh hari yaitu pada tanggal 23 Oktober sampai tanggal 31 Oktober 2018. Tabel 2 menjelaskan waktu dan tempat kegiatan sosialisasi yaitu pada tanggal 23 oktober 2018 dilakukan sosialisasi di ruangan melati dan mawar, 25 oktober dilakukan sosialisasi di ruangan dahlia dan cempaka, 30 oktober dilakukan sosialisasi di ruang laboratorium dan radiologi dan 31 oktober dilakukan sosialisasi di ruangan UGD dan apotik. 


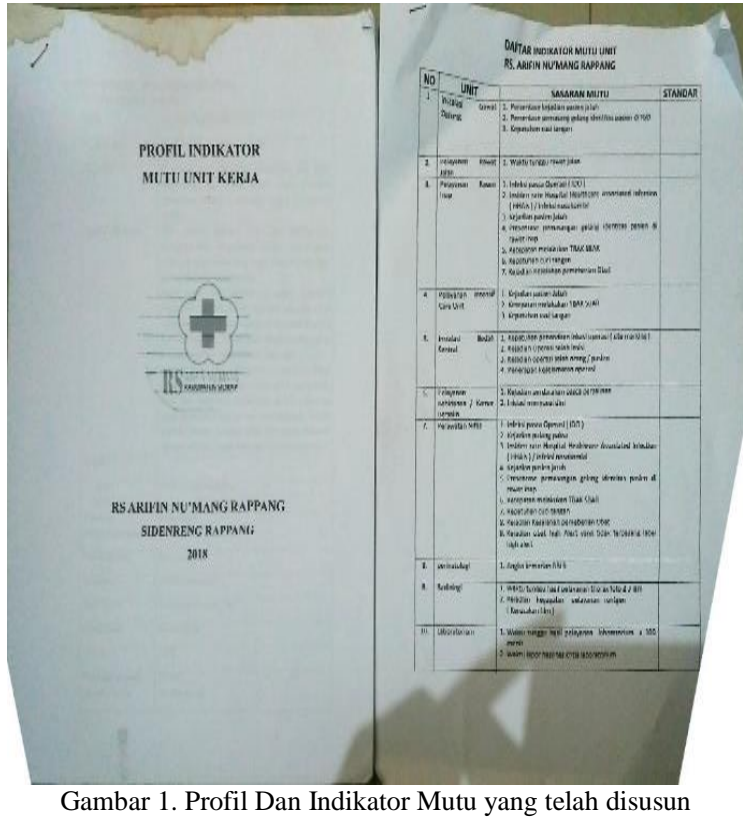

Menurut KARS, (2017) pelaporan budaya keselamatan juga perlu dilakukan oleh rumah sakit. Budaya keselamatan juga dikenal sebagai budaya yang aman, yakni sebuah budaya organisasi yang mendorong setiap individu anggota staf (klinis atau administratif) melaporkan hal-hal yang menghawatirkan tentang keselamatan atau mutu pelayanan tanpa imbal jasa dari rumah sakit. Gambar 2 merupakan kegiatan sosialisasi yang sedang dilakukan di salah satu unit rumah sakit.

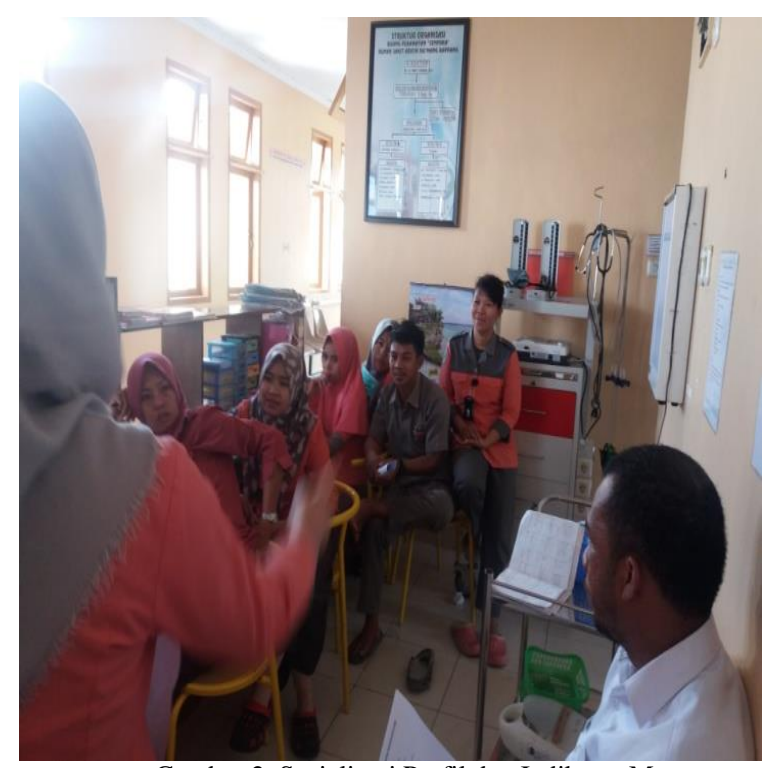

Gambar 2. Sosialisasi Profil dan Indikator Mutu

Setelah kegiatan ini dilakukan, terjadi peningkatan pengetahuan perawat tentang profil dan indikator mutu. Diagram 1 dapat dilihat rata-rata pengetahuan perawat sebelum mengikuti kegiatan dan setelah mengikuti kegiatan.

Diagram 1. Pengetahuan Perawat Pretest Dan Posttest Kegiatan Sosialisasi Profil dan Indikator Mutu Area Klinik di Rumah Sakit Arifin Nu'mang Tahun $2018(\mathrm{n}=39)$

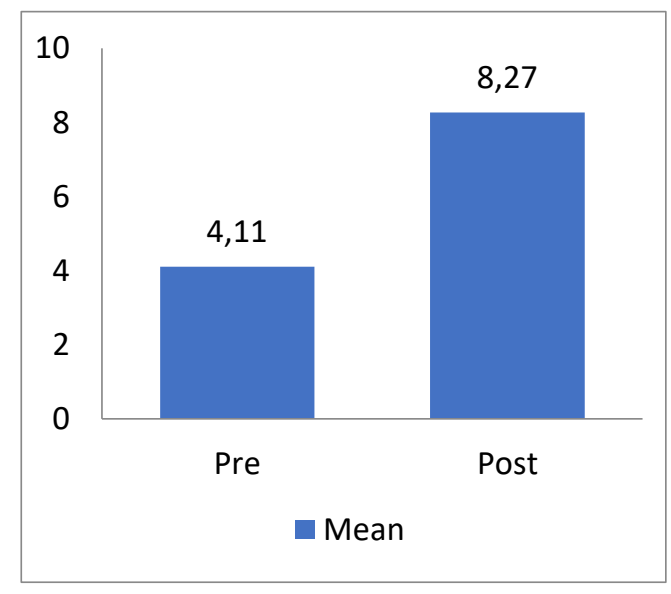

Berdasarkan Diagram 1. diatas, diperoleh gambaran pengetahuan perawat tentang sosialisasi profil dan indicator mutu area klinik sebelum seminar dengan rata-rata 4.11 (nilai terendah 2 dan nilai tertinggi 10), namun setelah dilaksanakan sosialisasi tentang SPO dan format supervise nilai rata-rata meningkat menjadi 8.27 (nilai terendah 4 dan nilai tertinggi 10). Dari hasil tersebut dapat disimpulkan bahwa terjadi peningkatan pengetahuan setelah dilakukan sosialisasi. Dapat diasumsikan bahwa sosialisasi memiliki pengaruh positif terhadap pengetahuan perawat.

3. Pendampingan pengisian format indikator mutu Pendampingan pengisian format indicator mutu klinik dilakukan selama 21 hari yaitu pada tanggal 23 Oktober sampai tanggal 16 november 2018.

Hasil program pendampingan pengisian format indicator-indikator mutu unit kerja RS Arifin Nu'mang Rappang dapat dilihat dari table pelaksanaan pelaporan indicator mutu di bawah ini: 
Tabel 2. Pelaporan Indikator Mutu dan Keselamatan pasien

\begin{tabular}{|c|c|c|}
\hline No & Unit (n) & $\begin{array}{c}\text { Jumlah Pelaporan } \\
\text { Indikator Mutu Setelah } \\
\text { Pendampingan }(\%)\end{array}$ \\
\hline 1. & UGD (3) & $2(66,67 \%)$ \\
\hline 2. & $\mathrm{ICU}(3)$ & $3(100 \%)$ \\
\hline 3. & Perinatologi(1) & $1(100 \%)$ \\
\hline 4. & Melati (7) & $5(71,43 \%)$ \\
\hline 5. & Anggrek (7) & $6(85,71 \%)$ \\
\hline 6. & Dahlia (7) & $2(28,57 \%)$ \\
\hline 7. & Cempaka (7) & $7(100 \%)$ \\
\hline 8. & Mawar (7) & $7(100)$ \\
\hline 9. & Radiologi (2) & $2(100 \%)$ \\
\hline 10. & Laboratorium (5) & $2(40 \%)$ \\
\hline \multicolumn{2}{|r|}{ Rata-rata } & $72,1 \%$ \\
\hline
\end{tabular}

Unit yang memiliki indikator mutu merupakan unit yang telah selesai dilakukan penyusunan indikator mutu oleh komite PMKP bersama dengan penulis, pelaporan sebelum dilakukan pendampingan merupakan pelaporan yang diberikan ke komite PMKP oleh masing-masing PIC unit yang telah ditentukan.

Tabel diatas menjelaskan bahwa UGD memiliki 3 indikator mutu namun pelaporan yang masuk hanya 2 indikator mutu yaitu sebesar $66,67 \%$. ICU memiliki 3 indikator mutu dan semua indicator mutu pelaporannya masuk yaitu sebesar $100 \%$. Perinatology memiliki 1 indikator mutu dan pelaporannya masuk yaitu sebesar $100 \%$. Ruang Melati memiliki 7 indikator mutu namun pelaporan yang masuk hanya 5 indikator mutu yaitu sebesar $71,43 \%$. Ruang anggrek memiliki 7 indikator mutu namun pelaporan yang masuk hanya 6 indikator mutu yaitu sebesar $85,71 \%$. Ruang dahlia memiliki 7 indikator mutu namun pelaporan yang masuk hanya 2 indikator yaitu sebesar 28,57\%. Ruang cempaka memiliki 7 indikator mutu namun pelaporan masuk hanya 2 indikator mutu yaitu sebesar $28,57 \%$. Ruang mawar memiliki 7 indikator mutu dan semua indicator mutu pelaporannya masuk yaitu sebesar 100. Ruang radiologi memiliki 2 indikator mutu dan semua indicator mutu pelaporanya masuk yaitu sebesar 100\%. Ruang laboratorium memiliki 5 indikator mutu namun pelaporan yang masuk hanya 2 yaitu sebesar 40\%. Rata-rata keseluruhan pelaporan yang masuk semua ruangan sebesar $72.1 \%$. Ada lima ruangan yang memiliki indicator mutu namun belum dilakukan pendampingan yaitu instalasi bedah sentral (4 indikator mutu ) Kamar bersalin ( 2 indikator mutu) nifas (3 indikator mutu) rekam medik (2 indikator mutu) rawat jalan (1 indikator mutu). Semua ruangan yang belum dilakukan pendampingan pengisian format indicator mutu dan keselamatan pasien juga belum memasukkan laporan indicator mutu di Komite PMKP.

Pelaporan indikator mutu setelah pendampingan merupakan pelaporan masing-masing unit oleh PIC yang diberikan kepada komite PMKP setelah selesai pendampingan pengisian indikator mutu dan keselamatan pasien.

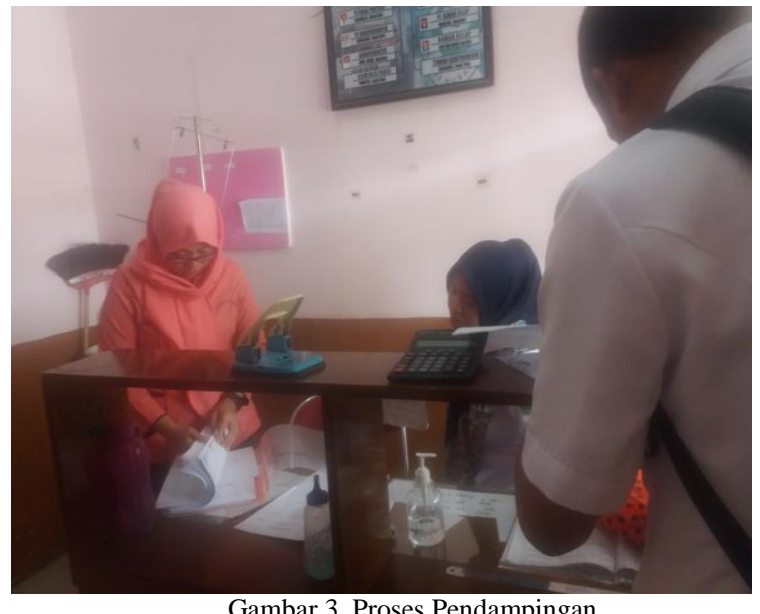

Gambar 3. Proses Pendampingan

Gambar 3 merupakan proses pendampingan pengisian format indikator mutu dan keselamatan pasien yang dilakukan di salah satu unit pelayanan kesehatan.

Ketiga kegiatan tersebut berefek pada perubahan yang terjadi dalam pelayanan keperawatan khususnya pelaporan indicator mutu unit di ruangan. Roger mengatakan bahwa perubahan yang efektif bergantung pada individu yang terlibat, tertarik, dan berupaya untuk selalu berkembang dan maju serta mempunyai suatu komitmen untuk bekerja dan melaksanakannya (Nursalam, 2015).

\section{KESIMPULAN}

Dari kegiatan penerapan pelaporan indikator mutu area klinik dapat disimpulkan yaitu: adanya profil dan indikator mutu area klinik RS, sosialisasi profil dan indikator mutu serta pendampingan pengisian format indikator mutu, Pengetahuan perawat di RS tentang PMKP khususnya pelaporan indikator mutu dan keselamatan pasien mengalami peningkatan dengan setelah dilakukan kegiatan sosialisasi serta membutuhkan komitmen yang tinggi dari perawat dan bidang yang terkait agar pelaksanaan pelaporan indikator mutu lebih optimal. Hasil pelaksanaan kegiatan dalam pengabdian ini secara umum meberikan dampak positif terhadap perubahan peningkatan mutu dan keselamatan pasien di RS. 


\section{UCAPAN TERIMA KASIH}

Kami mengucapkan terima kasih kepada Direktur Rumah Sakit, Seksi Keperawatan dan Komite PMKP yang telah berpartisipasi dalam proses kegiatan pengabdian ini dan pihak-pihak lain yang ikut serta mendukung dalam proses berjalannya kegiatan pengabdian ini.

\section{DAFTAR PUSTAKA}

[1] Departemen Kesehatan R.I. Panduan nasional keselamatan pasien rumah sakit (patient safety). 2006.

[2] Harsul, W., Syahrul. S., Majid. A. (2018). Penerapan Budaya Pelaporan Insiden Keselamatan Pasien di Sebuah RSU Daerah Provinsi Sulawesi Selatan. Jurnal Pandripta Abdi. Vol. 2(2). Hal:119-126. Retrived From: http://journal.unhas@ac.id/index.php/pandritaabdi

[3] Komisi Akreditasi Rumah Sakit. (2017). Standar Nasional Akreditasi Rumah Sakit. Edisi 1

[4] McFadden, K., Stephanie C., Charles R..The patient safety chain: transformationalleadership's effect on patient safety culture, initiatives, and outcomes. USA: Journal of operation management. Vol.27. 390-404. 2009

[5] Nursalam. (2015). Manajemen Keperawatan Aplikasi dalam Praktik Keperawatan Profesional(Ed. 5). Jakarta: Salemba Medika.

[6] RS Arifin Nu'mang. (2017). Profil rumah sakit Arifin Nu'mang Kabuaten Sidenreng Rappang tahun 2017. Rappang, Indonesia. 